\title{
Effect of fatty acid content on the level of cottonseed colonization by fungi
}

\author{
ALY ABD EL-HADY ALY ${ }^{1}$, EZZAT HUSSEIN ${ }^{1}$, MOAWAD OMAR ${ }^{1}$, \\ IBRAHIM EL-ABBASI ${ }^{1}$ and KAMEL ABD-ELSALAM ${ }^{2}$
}

\author{
${ }^{1}$ Agricultural Research Centre, Plant Pathology Research Institute, Giza, Egypt \\ ${ }^{2}$ King Saud University, College of Science, Botany and Microbiology Department, P.O. Box: 2455, \\ Riyadh 1145, Saudi Arabia \\ Corresponding author: Kamel Abd-Elsalam, abd-elsalam.k.a@post.com
}

(Received on 8 June 2010; Accepted on 14 February 2011)

\begin{abstract}
Non-sterilized seeds of 12 Egyptain cotton (Gossypium barbadense L.) genotypes were examined for qualitative and quantitative estimates of seed-borne fungi. Rhizopus stolonifer (39.7\%), Aspergillus niger (33.5\%), and Penicillium sp. (23.3\%) were the most predominant fungi isolated from the seeds. Other fungi occurred at frequencies that ranged from 0.3 to $17.7 \%$. Gas-liquid chromatography (GLC) analysis of fatty acid composition of the seeds revealed the presence of the following fatty acids: caproic, caprylic, capric, lauric, myristic, palmitic, margaric, stearic, oleic, linoleic, and linolenic. The total mean percentage of the monounsaturated fatty acids was $59.11 \%$, while that of the unsaturated fatty acids was $16.72 \%$. Isolation frequencies of Alternaria alternata, A. flavus, A. niger were not significantly correlated with the content of any fatty acid. Isolation frequencies of the other fungi were significantly correlated with the content of 1-2 fatty acids. Cladosporium sp. was a notable exception because its isolation frequency was significantly correlated with the content of caproic $(r=0.926, p<0.01)$, caprylic $(r=0.638$, $p<0.05)$, palmitic $(r=-0.586, p<0.05)$, and linoleic acid $(r=0.917, p<0.01)$. It was possible to group the isolated fungi into 5 distinct categories based on their sensitivity to the fatty acids (the magnitude of $R^{2}$ values). The results of the present investigation suggest that certain fatty acids regulate the colonization of cottonseed by fungi, and that the control of these fungi may be possible by modifying the fatty acid content of the seed.
\end{abstract}

Keywords: Cottonseed, fatty acid composition, seed-borne fungi

\section{INTRODUCTION}

The economic value of cottonseed is greatly influenced by the presence of fungi in the seed. Fungi or associated metabolites may reduce seed vigour (Halloin \& BOURLAND 1981; DAVIS 1982) and increase the amount of free fatty acids in the seed, thereby reducing the quality of the oil (RONCADORI et al. 1971), or produce mycotoxins that render the seed unsuitable for consumption (DiENER et al. 1976).

Under Egyptian conditions, the fungi involved in cottonseed deterioration include Alternaria spp., Aspergillus spp., Cephalosporium spp., Cladosporium spp., 
Curvularia spp., Fusarium moniliforme, F. oxysporum, F. semitectum, F. solani, Helmenthosporium spp., Nigrospora spp., Pythium spp., Rhizoctonia spp., Trichothecium spp., Epicoccum spp., Penicillium spp., Chaetomium spp., Diplodia gossypii, Rhizopus spp., and others (El-Helaly et al.1966; WaKed et al. 1981; Amer 1986; MoHAMED-Hoda et al. 1999).

Cottonseed oil contains higher proportions of saturated fatty acids $(24.6 \%)$ than soybean oil (14.7\%), and canola oil (6.1\%) (SALUNKHE et al. 1992). Fatty acids, ubiquitous in nature, play a crucial role in life processes. The acids are involved in cell energy storage, membrane structure, and various signalling pathways. In addition, fatty acids in animal fat, plant oil, and other sources are an important part of human nutrition (LiU et al. 2008).

A number of fatty acids have been shown to inhibit or stimulate the growth and sporulation of pathogenic fungi in plants. For example, laboratory tests showed that active fractions from cottonseed extract (cv. Acala SJ-2), containing unsaturated fatty acids, induced high levels of germination in Pythium ultimum isolate P4, whereas several saturated analogues did not (RutTledge \& Nelson 1997). CAlvo et al. (1999) found sporogenic effects of polyunsaturated fatty acids on the development of Aspergillus spp. HARMAN et al. (1980) found that palmitic acid stimulated germination of conidiospores of Fusarium solani f. sp. pisi, in addition to oleic and linoleic acids, while stearic and linolenic acids were ineffective. Mycelial growth of Rhizoctonia solani and P. ultimum in agar culture was significantly reduced by lauric acid at concentrations of $100 \mu \mathrm{M}$ and above, while no fungal growth occurred in liquid culture at concentrations above $50 \mu \mathrm{M}$ (Walters et al. 2003). The effects of linolenic, linoleic, erucic, and oleic acids on the growth of the plant-pathogenic fungi $R$. solani, $P$. ultimum, Pyrenophora avenae, and Crinipellis perniciosa were examined in vitro by WALTERS et al. (2004). The antifungal activities of 9 fatty acids (butyric, caproic, caprylic, capric, lauric, myristic, palmitic, oleic, and linoleic) against 4 phytopathogenic fungi: Alternaria solani, Colletotrichum lagenarium, Fusarium oxysporum $\mathrm{f}$. sp. cucumerinum, and F. oxysporum f. sp. lycopersici, were assessed by measuring mycelial growth and spore germination via Petri dish assay (Liu et al. 2008). Except for oleic acid, the fatty acids tested were observed to inhibit mycelial growth of one or more tested fungi. In addition to the suppression of mycelial growth, butyric, caproic, caprylic, capric, lauric, and palmitic acid showed an inhibitory effect on spore germination, and the extent of inhibition varied with both the type of fatty acids and the fungal species. In particular, capric acid displayed a strong inhibitory effect against $C$. lagenarium. The saturated fatty acids, e.g. palmitic acid, showed stronger antifungal activity than the unsaturated fatty acids, e.g. oleic acid.

Fatty acids have also been shown to be correlated with resistance or susceptibility to plant diseases. Pinus sylvestris seed, containing more unsaturated fatty acids and a large amount of erucic acid, were more resistant to damping-off fungi (GRzYWACZ \& RosochacKa 1977). The oleic and linolenic acid content in the cotyledons of cotton were correlated with Fusarium wilt resistance, with significant differences in fatty acid content existing between wilt-resistant and susceptible varieties. Oleic acid content of cotyledons, which is positively correlated with wilt resistance, was the highest in the resistant variety $52-128(59.5 \%)$, while linolenic acid content in 
cotyledons, which is negatively correlated with wilt resistance, was the lowest in variety 52-128 (18\%) (Guo et al.1991). Lauric acid at concentrations ranging from 250 to $1000 \mu \mathrm{M}$, applied to barley leaves (before or after inoculation with Blumeria graminis f. sp. hordei), has led to significant reductions in infection rate (WALTERS et al. 2003). Colonization of soybean seed by Cercospora kikuchii was positively correlated with the oleic:linoleic ratio $(r=0.55, p<0.03)$ and oleic acid content $(r=0.61$, $p<0.02)$, and negatively correlated with linoleic $(r=-0.60, p<0.02)$ and linolenic $(r=-0.58, p<0.03)$ acid content (XUE et al. 2008).

Little is known about the constituents of cottonseed that affect its susceptibility to fungi. However, one report has demonstrated that dormant cottonseed contains proteins capable of inhibiting the activity of proteolytic enzymes of the pathogen Verticillium dahliae (Mezhlum-YAN et al. 1994). The considerable body of work with fatty acids has provided convincing evidence that fatty acids may play an important role in regulating the interaction of fungi with cottonseed. Therefore, the main objective of the present study was to evaluate the role of fatty acids in determining the level of cottonseed colonization by fungi. An understanding of such a potential role could lead to a better of control the seed-borne fungi, which devalue cottonseed.

\section{MATERIALS AND METHODS}

\section{Fungal profiles of cotton genotypes}

Random samples of Egyptian cotton (Gossypium barbadense L.) genotypes were obtained from the Cotton Research Institute, Agricultural Research Center, Giza, Egypt. A random subsample of 100 seeds of each genotype was used for isolation. Occurrence of seed-borne fungi was determined by the standard blotter method (ISTA 1993). Ten non-sterilized seeds for each genotype, selected at random, were placed on 3 layers of damp 9-cm Whatman No. 1 filter paper in Petri dishes, and each was replicated 10 times. The plates were incubated in 12-h photoperiod (cool white light) at $20 \pm 2^{\circ} \mathrm{C}$ for 7 days. After incubation, each colony was examined macroscopically or microscopically for identification to genus or species level according to GILMAN (1966), BOOTH (1971), or BARNETT \& HuNTER (1979). Isolation frequency of each fungus was expressed as the percentage of seeds from which the fungus grew. If more than one fungus grew from the same seed, each was counted.

\section{Analysis of seed fatty acid composition}

Fatty acids were separated from the lipid fraction of the seed samples (FARAG et al. 1986) and converted to methyl esters by using ethereal solution of diazomethane. Next, $10 \mathrm{mg}$ of fatty acids were dissolved in $0.5 \mathrm{ml}$ of anhydrous diethyl ether, and methylated by drop-wise addition of diazomethane solution until the appearance of yellow colour (Vogel 1975). The mixture was then left at room temperature for 15 min, and the solvent was evaporated on a water bath maintained at $60^{\circ} \mathrm{C}$. Finally, the methyl esters of fatty acids were dissolved in pure chloroform, and aliquots of this solution were subjected to gas liquid chromatography (GLC) by using Pye Unicam-Pro-GC equipped with a dual flame ionization detector. Acid methyl esters were fractionated using a coiled glass column $(1.5 \mathrm{~m} \times 4 \mathrm{~mm})$, packed with diatomite $\mathrm{C}$ 
(100-120 mesh), and coated with 10\% polyethylene glycol adipate (PEGA). The column oven temperature increase was programmed at $8^{\circ} \mathrm{C} / \mathrm{min}$ from 70 to $190^{\circ} \mathrm{C}$, then isothermally at $190^{\circ} \mathrm{C}$ for $45 \mathrm{~min}$. The carrier gas was nitrogen with $30 \mathrm{ml} / \mathrm{min}$ flow rate. Temperatures were 300 and $280^{\circ} \mathrm{C}$ for the detector and the injector, respectively. Fatty acid contents were calculated from chromatogram peak areas and expressed as percentage $(w / w)$ of the total fatty acids.

\section{Statistical analysis of the data}

Linear correlation coefficient was calculated to evaluate the degree of association between frequencies of the isolated fungi and the percentage of each fatty acid. Stepwise regression with the greatest increase in $R^{2}$ as the decision criterion was used to describe the effect of fatty acids on frequencies of the isolated fungi. Correlation and regression analyses were performed by SPSS software.

\section{RESULTS}

The mean percentage of fungal recovery from cottonseed (Table 1) showed that R. stolonifer (39.7\%), A. niger (33.5\%), and Penicillium sp. (23.3\%), were the most predominant fungi isolated from the non-sterilized cottonseed. Other fungi occurred at frequencies that ranged from 0.3 to $17.7 \%$. A total of 10 fungal species were identified among the 12 genotypes that were tested (Table 1). No single genotype yielded all the 10 species. Genotype 488/2000 yielded as many as 8 species, while genotypes $514 / 2000$ and Giza 74 yielded only 4 species. The other genotypes yielded 5 to 7 species. $R$. stolonifer was the only fungus isolated from all the tested genotypes.

GLC analysis of fatty acid composition of cottonseed (Table 2) revealed the presence of 8 saturated and 3 unsaturated fatty acids. Palmitic acid was the only fatty acid detected in all the genotypes. No single genotype contained all the fatty acids. The total mean percentage of the saturated fatty acids was $59.11 \%$, while that of the unsaturated fatty acids was $16.72 \%$. Of the saturated fatty acids, palmitic $(24.71 \%)$, margaric $(11.63 \%)$, and stearic $(16.40 \%)$ were predominant, while oleic acid $(15.48 \%)$ was the dominant unsaturated fatty acid in cottonseed oil.

Of the 13 significant $r$ values shown in Table 3 , as many as $11(84.6 \%)$ were positive, while only $2(15.4 \%)$ were negative. Isolation frequencies of Alternaria alternata $\left(\mathrm{Y}_{1}\right)$, Aspergillus flavus $\left(\mathrm{Y}_{2}\right)$, and A. niger $\left(\mathrm{Y}_{3}\right)$ were not significantly correlated with the content of any fatty acid, while the isolation frequency of each of the other fungi was significantly correlated with the content of 1-2 fatty acids. Cladosporium sp. $\left(\mathrm{Y}_{5}\right)$ was a notable exception because its isolation frequency was significantly correlated with the contents of 4 fatty acids (Table 3 ).

Levels of fatty acids were significantly correlated with the isolation frequencies of 1-2 fungal species, except palmitic acid content, which was significantly correlated with the isolation frequency of 3 species: Cladosporium sp. $\left(\mathrm{Y}_{5}\right)$, F. oxysporum $\left(\mathrm{Y}_{6}\right)$, and $R$. stolonifer $\left(\mathrm{Y}_{8}\right)$.

Data for frequencies of the isolated fungi and contents of fatty acids were subjected to a computerized stepwise multiple regression analysis. The analysis constructed a predictive model by adding predictors (in this case: fatty acids) to the 


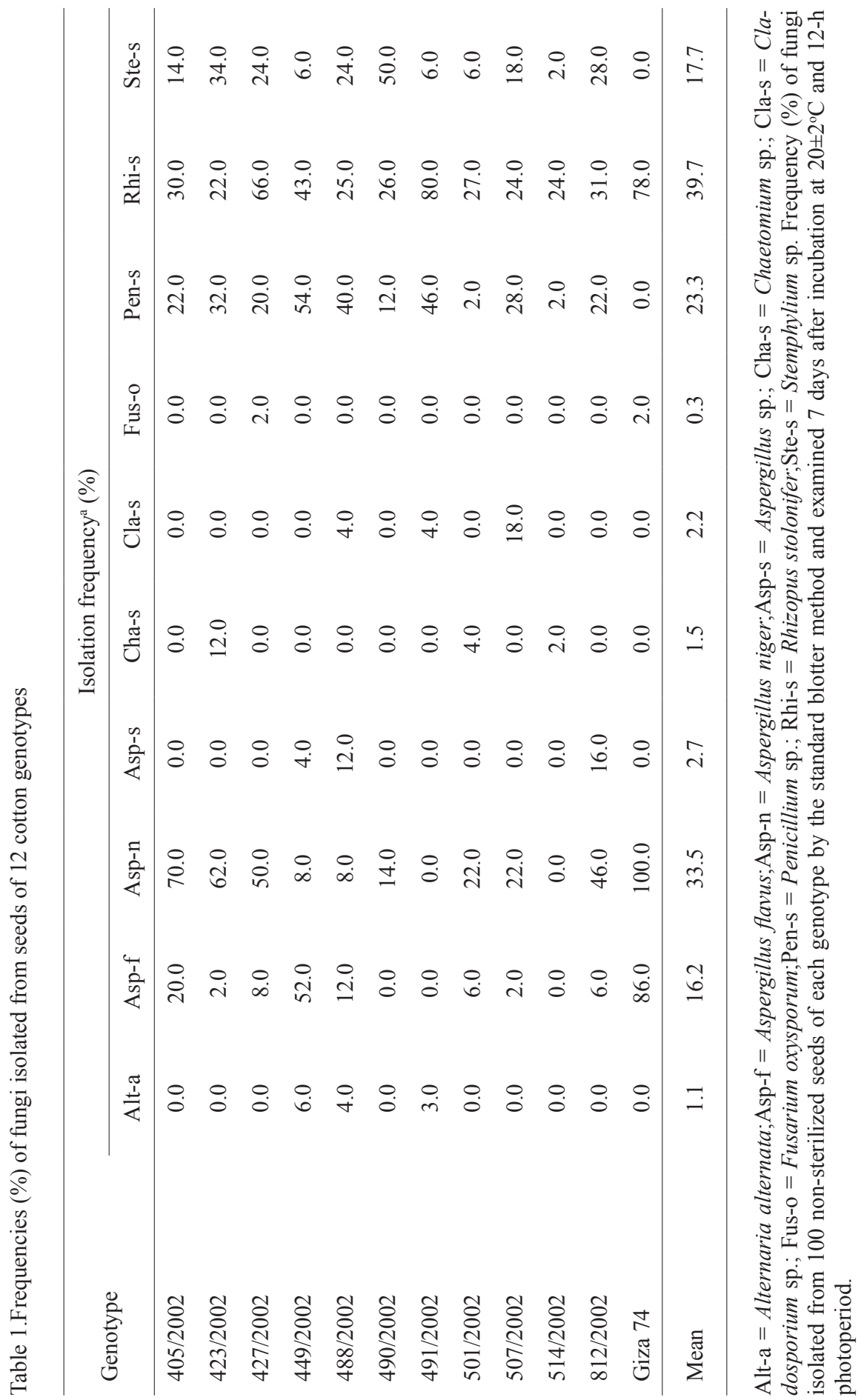




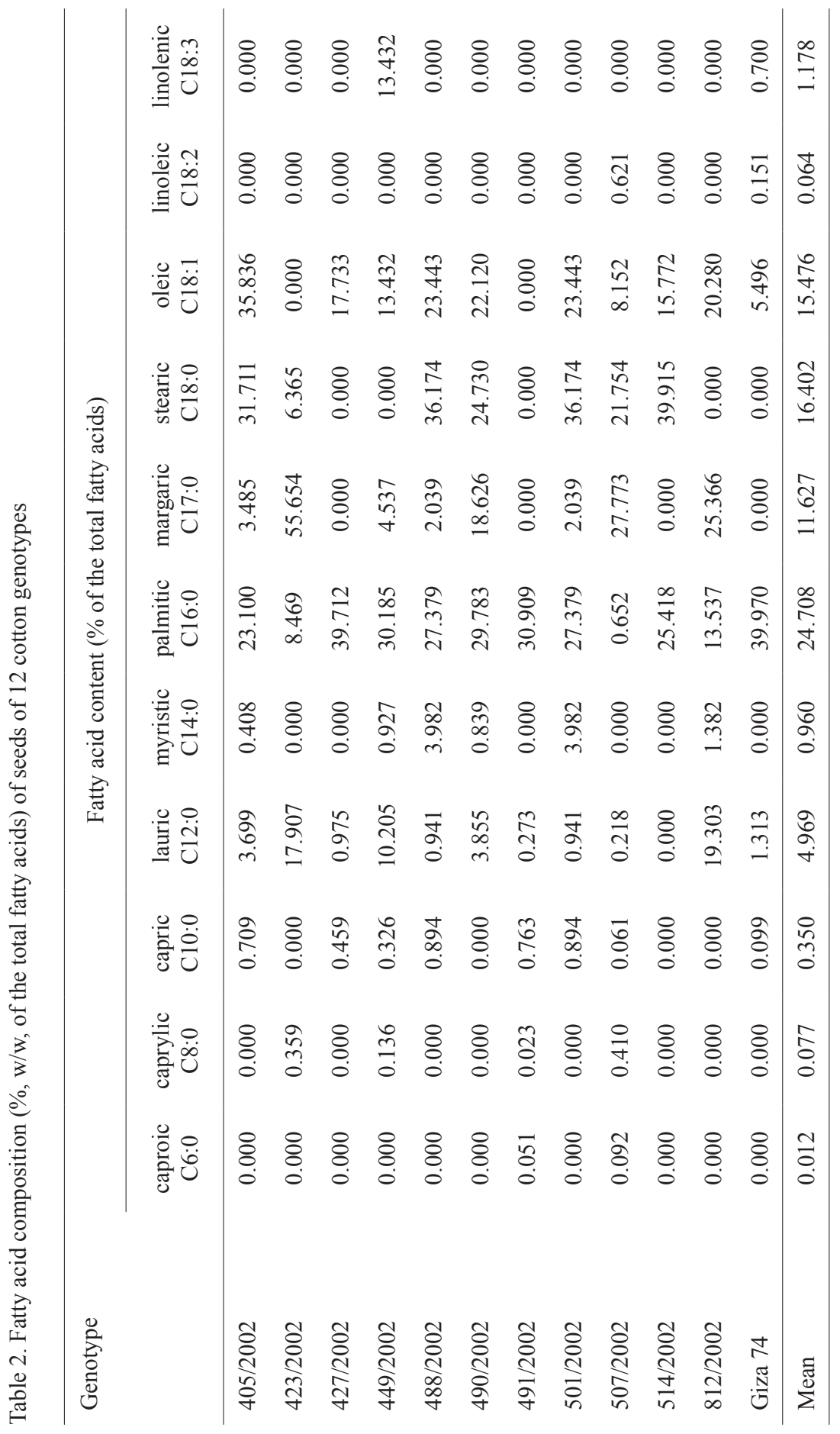




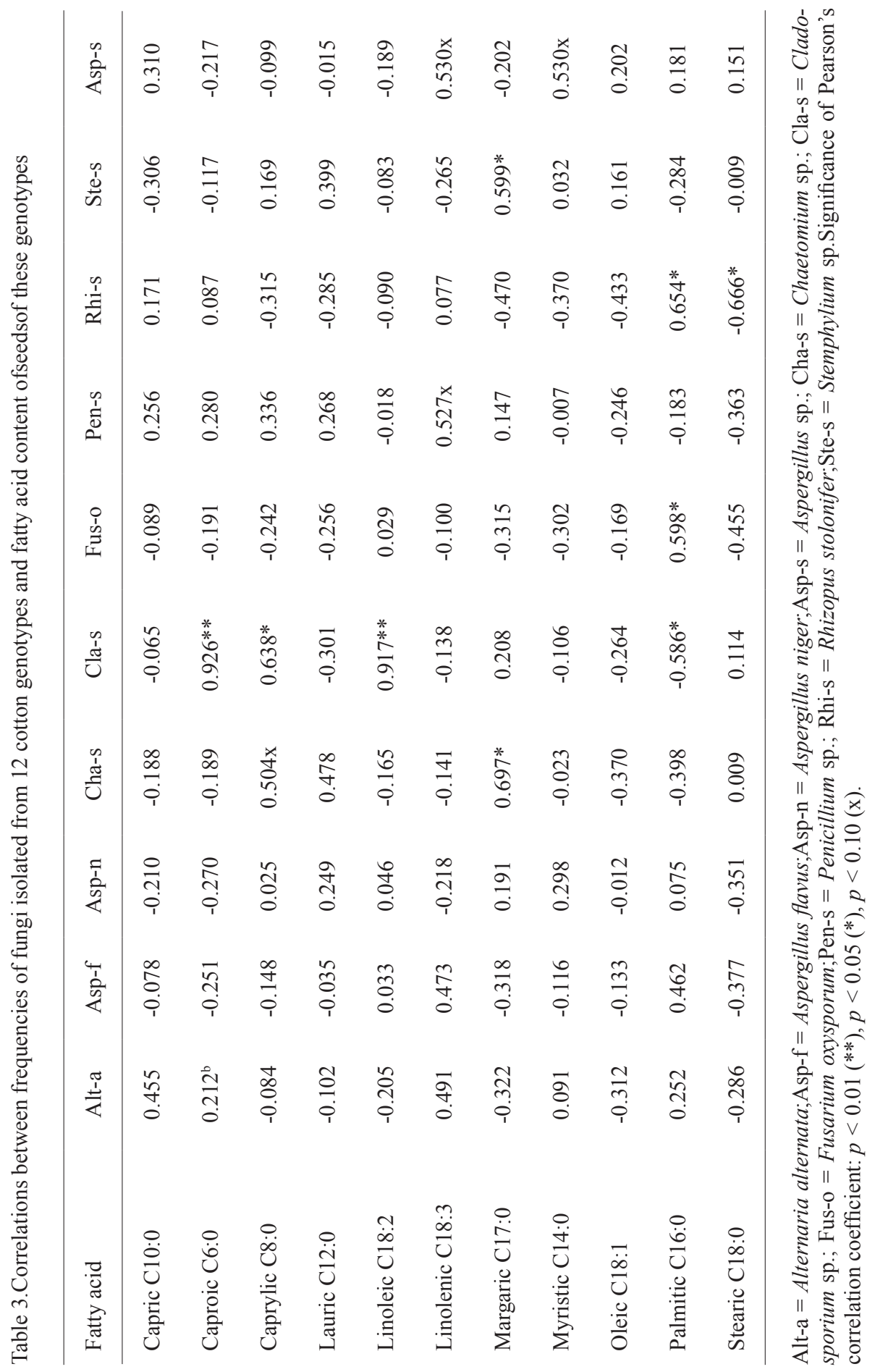


Table 4. Stepwise regression models that describe the effect of fatty acid content $\left(\mathrm{X}_{\mathrm{s}}\right)$ of seeds from 12 cotton genotypes on frequencies of fungi isolated from these genotypes

\begin{tabular}{|c|c|c|c|}
\hline Species & Stepwise linear regression model & $R^{2}(\%)$ & $F$ \\
\hline A. niger & N/A & N/A & N/A \\
\hline Alternaria alternata & $Y=1.46+0.35 \mathbf{X}_{11}+4.98 \mathbf{X}_{3}-0.14 \mathbf{X}_{\mathbf{9}}$ & 69.03 & $5.94 *$ \\
\hline Aspergillus flavus & N/A & N/A & N/A \\
\hline Aspergillus sp. & $Y=-0.14+0.77 \mathbf{X}_{11}+1.99 \mathbf{X}_{5}$ & 57.14 & $6.00 *$ \\
\hline Chaetomium sp. & $Y=-0.16+0.14 \mathrm{X}_{7}$ & 48.51 & $9.42 *$ \\
\hline Cladosporium sp. & $Y=-0.58+103.04 \mathbf{X}_{1}+14.05 \mathbf{X}_{10}+0.64 \mathbf{X}_{5}$ & 95.94 & $62.94 * * *$ \\
\hline Fusarium oxysporum & $Y=-2.53+0.09 \mathbf{X}_{6}+2.80 \mathbf{X}_{10}+0.03 \mathbf{X}_{7}$ & 67.92 & $5.65^{*}$ \\
\hline Penicillium sp. & $\mathrm{Y}=20.50+2.41 \mathbf{X}_{11}$ & 27.80 & $3.85 \mathrm{x}$ \\
\hline Rhizopus stolonifer & $Y=74.48-1.31 \mathbf{X}_{8}-2.07 \mathbf{X}_{4}-40.18 \mathbf{X}_{2}$ & 93.62 & $39.13^{* * *}$ \\
\hline Stemphylium sp. & $\mathrm{Y}=11.75+0.94 \mathbf{X}_{7}-64.23 \mathbf{X}_{2}$ & 53.66 & $5.21 *$ \\
\hline
\end{tabular}

$\mathrm{R}^{2}=$ coefficient of determination. Fatty acids: $\mathrm{X}_{1}=$ caproic; $\mathrm{X}_{2}=$ caprylic; $\mathrm{X}_{3}=$ capric; $\mathrm{X}_{4}=$ lauric; $\mathrm{X}_{5}=$ myristic; $\mathrm{X}_{6}=$ palmitic $; \mathrm{X}_{7}=$ margaric; $\mathrm{X}_{8}=$ stearic; $\mathrm{X}_{9}=$ oleic; $\mathrm{X}_{10}=$ linoleic; $\mathrm{X}_{11}=$ linolenic. $\mathrm{N} / \mathrm{A}=$ no regression model could be constructed.Significance of $\mathrm{F}$-values: $p<0.10(\mathrm{x}) ; p<0.05$ $(*) ; p<0.005(* * *)$.

model, in the order of their contribution to $R^{2}$. The analysis was effective in eliminating those factors with little or no predictive value, by incorporating into the model only the factors that made a statistically significant contribution to the $R^{2}$ value of the model (PoDLECKIs et al. 1984). Using the predictors supplied by stepwise regression, 8 models were constructed (Tables 4 and 5). $R^{2}$ values of the regression models ranged from 27.80 to $95.94 \%$. Margaric acid $\left(\mathrm{X}_{7}\right)$ and linolenic acid $\left(\mathrm{X}_{11}\right)$ were included in 3 models each, while caprylic acid $\left(\mathrm{X}_{2}\right)$, myristic acid $\left(\mathrm{X}_{5}\right)$, and linoleic acid $\left(\mathrm{X}_{10}\right)$ were included in 2 models each. Each of the remaining fatty acids was included in only one model. 
Table 5. Identification of the predictors (fatty acid contents) included in stepwise regression models shown in Table 4, and their contributions (\%) to the total variation in frequencies of the isolated fungi

\begin{tabular}{|c|c|c|}
\hline Fungus and predictor & Predictor symbol & $\begin{array}{l}\text { Contribution to } \\
\text { total variation (\%) }\end{array}$ \\
\hline \multicolumn{3}{|l|}{ Alternaria alternata } \\
\hline linolenic $\mathrm{C} 18: 3$ & $\mathbf{X}_{11}$ & 24.13 \\
\hline capric $\mathrm{C} 10: 0$ & $\mathbf{X}_{3}$ & 22.17 \\
\hline oleic C18:1 & $\mathbf{X}_{9}$ & 22.72 \\
\hline \multicolumn{3}{|l|}{ Chaetomium sp. } \\
\hline margaric $\mathrm{C} 17: 0$ & $\mathbf{X}_{7}$ & 48.51 \\
\hline \multicolumn{3}{|l|}{ Cladosporium sp. } \\
\hline caproic C6:0 & $\mathbf{X}_{1}$ & 85.66 \\
\hline linoleic C18:2 & $\mathbf{X}_{10}$ & 7.24 \\
\hline myristic $\mathrm{C} 14: 0$ & $\mathbf{X}_{5}$ & 3.03 \\
\hline \multicolumn{3}{|l|}{ Fusarium oxysporum } \\
\hline palmitic C16:0 & $\mathbf{X}_{6}$ & 35.77 \\
\hline linoleic C18:2 & $\mathbf{X}_{10}$ & 17.31 \\
\hline margaric $\mathrm{C} 17: 0$ & $\mathbf{X}_{7}$ & 14.85 \\
\hline \multicolumn{3}{|l|}{ Penicillium sp. } \\
\hline linolenic $\mathrm{C} 18: 3$ & $\mathbf{X}_{11}$ & 27.80 \\
\hline \multicolumn{3}{|l|}{ Rhizopus stolonifer } \\
\hline stearic $\mathrm{C} 18: 0$ & $\mathbf{X}_{8}$ & 44.28 \\
\hline lauric $\mathrm{C} 12: 0$ & $\mathbf{X}_{4}$ & 42.56 \\
\hline caprylic C8:0 & $\mathbf{X}_{2}$ & 6.77 \\
\hline \multicolumn{3}{|l|}{ Stemphylium sp. } \\
\hline margaric $\mathrm{C} 17: 0$ & $\mathbf{X}_{7}$ & 35.82 \\
\hline caprylic C8:0 & $\mathbf{X}_{2}$ & 17.84 \\
\hline \multicolumn{3}{|l|}{ Aspergillus sp. } \\
\hline linolenic $\mathrm{C} 18: 3$ & $\mathbf{X}_{11}$ & 28.08 \\
\hline myristic $\mathrm{C} 14: 0$ & $\mathbf{X}_{5}$ & 29.06 \\
\hline
\end{tabular}

\section{DISCUSSION}

The predominance of Aspergillus niger over the other fungi isolated from cottonseed, except Rhizopus stolonifer, is consistent with the findings of SIMPSON et al. (1973) who reported that $A$. niger was a predominant fungus at several locations in their study, infecting up to $23 \%$ of the seeds. R. stolonifer and Penicillium sp. are among the fungi involved in cotton boll rot and may cause deterioration in fibre qual- 
ity under favourable environmental conditions (AвDEL-Reнim et al.1993). Cladosporium sp. is involved in sooty mould of cotton (ZAYED 1997). Alternaria has been reported as a predominant member of the mycoflora of cottonseed by DAVIS (1977). However, Alternaria was listed as an infrequent fungus by RONCADORI et al. (1971), and was present in more than $10 \%$ of the seeds from only one location in the study of Simpson et al. (1973). KLich (1986) found A. alternata in more than $10 \%$ of the seeds. In the present study, A. alternata was found in $1.1 \%$ of the seeds. Generally, Fusarium spp. were major components of the fungal flora in earlier studies (SIMPSON et al. 1973, RONCADORI et al. 1971). In the present study, F. oxysporum was found in $0.3 \%$ of the seeds.

The predominance of saturated fatty acids in cottonseed oil, as we have demonstrated herein, is in agreement with the results of SALUNKHE et al.(1992) who reported that cottonseed oil contained higher proportions of saturated fatty acids $(24.6 \%)$ as compared with soybean oil (14.7\%) and canola oil (6.1\%).

In the present study, associations among fatty acids and fungi isolated from cottonseed were identified, and the relative strength of these associations was measured by calculating Pearson's correlation coefficient $(r)$. However, one should keep in mind that the significant $r$ values should be interpreted with caution (GoMEZ \& GoMEZ 1984) because the existence of a process may not be proved by the existence of a pattern (Nelson \& CAMPBell 1992). In other words, the significant positive or negative $r$ value does not necessarily prove that fatty acids are beneficial or detrimental to fungi. Thus, the primary utility of correlation analysis was to identify the potentially interactive pairs of fatty acids and fungi. The interpretation of the nature of such interactions requires information about the metabolic pathways of fungi and biological activities of fatty acids. In spite of these limitations, certain general conclusions could be drawn. The positive $r$ value may indicate that fatty acids had stimulatory effects on the growth and sporulation of cottonseed fungi. On the other hand, the negative $r$ value could be attributed to inhibitory activities of fatty acids. These causal relationships between fatty acids and seed-borne fungi are consistent with biological expectations. For example, fatty acids have been shown to be growth stimulants and a carbon source for Phytophthora parasitica var. nicotianae (HENDRIX \&APPLE 1964). Volatile peroxidation products of the fatty acids, e.g. 2,4-hexadienal, may stimulate spore germination of Alternaria alternata (HARMAN et al. 1978, 1980). Linoleic acid and plant-derived linoleic acid derivatives have specific effects on the development of Aspergillus spp., which are likely to be important for the ability of this pathogen to colonize peanut seed. These effects include the induction of increased sporulation in A. flavus and A. parasiticus, and altered sclerotium production in A. flavus (CALvo et al. 1999, 2001). On the other hand, the antifungal activities of fatty acids could be attributed to fungal membrane disruption (Avis \& BÉLANGER 2001; BERGSSONet al.2001) or interference with fungal sphingolipid biosynthesis (Li et al. 2003).

Isolation frequencies of $A$. flavus and A. niger were not significantly correlated with any fatty acid. This lack of correlations in addition to the inability to generate regression models for the 2 fungi were surprising because linoleic acid, as previously mentioned, induces sporulation of Aspergillus spp. (CALvo et al. 1999, 2001). No immediate biological explanation is available for the discrepancy between our results 
and those of CALvo et al. (1999, 2001). On the other hand, the significant positive correlation $(r=0.530, p<0.10)$ between linolenic acid and isolation frequency of Aspergillus sp. was in agreement with the results of WiLSON et al. (2004), who reported that an Aspergillus mutant unable to produce linolenic acid demonstrated delayed spore germination, reduced growth, a reduced level of sporulation, and a complete loss of sclerotial development, as compared with the wild type. Colonization of peanut seed by the mutant was lower than in the wild type.

$R^{2}$ values of the regression models ranged from 27.80 to $95.94 \%$. Obviously, the larger the $R^{2}$ value is, the stronger is the fungus response to fatty acids. The isolated fungi can be grouped into 5 categories based on their sensitivity to changes in total fatty acid content. The first category includes the insensitive fungi $A$. flavus and $A$. $n i$ ger, where no regression models could be constructed. The second category comprises the slightly sensitive Penicillium sp., which has the smallest $R^{2}$ value $(27.80 \%)$. The third category - moderately sensitive fungi - contains Chaetomium sp., Stemphylium sp., and Aspergillus sp., where $R^{2}$ values are 48.51, 53.66, and 57.14\%, respectively. The fourth category includes the sensitive fungi $A$. alternata and $F$. oxysporum, where $R^{2}$ values are 69.03 and $67.92 \%$, respectively. Both species of the fifth category are highly sensitive: Cladosporium sp. and $R$. stolonifer, where $R^{2}$ values are 95.94 and $93.62 \%$, respectively. However, these 2 species showed contradictory responses to the fatty acids. An increase in the isolation frequency of Cladosporium sp. was associated with increasing fatty acid contents, while an increase in the isolation frequency of $R$. stolonifer was associated with decreasing fatty acid contents. Thus, fatty acids were stimulatory to Cladosporium $\mathrm{sp}$. while they were inhibitory to $R$. stolonifer.

In conclusion, results of the present study suggest that certain fatty acids regulate the colonization of cottonseed by fungi, and that these pathogens may be controlled by modifying the fatty acid composition and content of the seed.

\section{REFERENCES}

Abdel-Rehim S., Aly, A. A., Eisa H. A., Zenab M. A.1993. Deterioration of cotton fibers caused by some cellulolytic fungi isolated from rotted cotton bolls. Menofyia J. Agric. Res.18: $2095-2110$.

Amer M. A. A.1986. Studies on cotton-seed infection by fungi. M.Sc. Thesis, Helwan University, Alexandria.

Avis T. J., Bélanger R. R. 2001. Specificity and mode of action of the antifungal fatty acid cis9-heptadecenoic acid produced by Pseudozyma flocculosa. Appl. Environ. Microbiol. 67: 956-960.

Barnett H. L., Hunter B. B. 1979. Illustrated genera of imperfect fungi, $3^{\text {rd }}$ ed. Burgess Publishing Company, Minneapolis, Minnesota.

Bergsson G., Arnfinnsson J., Steingrimsson O., Thormar H. 2001. In vitro killing of Candida albicans by fatty acids and monoglycerides. Antimicrob. Agents Chemother. 45: 3209-3212.

Воотн C. 1971. The genus Fusarium. Commonwealth Mycological Institute, Kew, Surrey, England.

Calvo A. M., Gardner H. W., Keller N. P. 2001. Genetic connection between fatty acid metabolism and sporulation in Aspergillus nidulans. J. Biol. Chem. 276: 25766-25774. 
Calvo A. M., Hinze L. L., Gardner H. W., Keller N. P. 1999. Sporogenic effect of polyunsaturated fatty acids on development of Aspergillus spp. Appl. Environ. Microbiol. 65: 3668-3673.

DAvis R. G. 1977. Fusarium species in the internal microflora of Mississippi cottonseed. Seed Sci. Technol. 5: 587-591.

DAvis R. G.1982. Relationships between seedborne microorganisms and cotton seedling emergence. Mississippi Agricultural and Forest Experimental Station Research Report No. 7: 1-3.

Diener U. L., Wagener R. E., Morgan-Jones G., Davis N. D. 1976. Toxigenic fungi from cotton. Phytopathology 66: 514-516.

El-Helaly A. F., Ibrahim I. A., Asswah M. W., Wasfi E. H., El-Goorani M. A. 1966. General survey of plant diseases and pathogenic organisms in Egypt until 1966. Alex. J. Agric. Res. 15: 61.

Farag R. S., Hallabo S. A. S., Hewedi F. M., Basyony A. E. 1986. Chemical evaluation of rape seed. Fette-Scifen Anstrichmittel 88: 391-397.

Gilman J. C. 1966. A manual of soil fungi, $2^{\text {nd }}$ ed. The Iowa State University Press, Iowa.

Gomez K. A., Gomez A. A. 1984. Statistical procedures for agricultural research, $2^{\text {nd }}$ ed. John Wiley and Sons Ltd., New York.

Grzywacz A., Rosochacka J. 1977. Attempt at elucidation of the role of fatty acids in the resistance of Pinus sylvestris L. seeds to infection by damping-off fungi in dependence on the colour of their seed shells (coats). Acta Soc. Bot. Polon. 46: 569-575.

Guo J. C. Song X. X., Zhang J. X. Li C. B. 1991. Correlation of fatty acid components variation in cotton tissues with Fusarium wilt resistance. China Cottons 2: 46-48.

Halloin J. M., Bourland F. M. 1981. Deterioration of planting seed. In: Compendium of cotton diseases (Watkins G.M., Ed.), pp. 11-13,The American Phytopathological Society, St. Paul, Minnesota.

Harman G. E., Nedrow B., Nash G. 1978. Stimulation of fungal spore germination by volatiles from aged seeds. Can. J. Bot. 56: 2124-2127.

Harman G. E., Mattick L. R., Nash G., Nedrow B. L. 1980. Stimulation of fungal spore germination and inhibition of sporulation in fungal vegetative thalli by fatty acids and their volatile peroxidation products. Can. J. Bot. 58: 1541-1547.

Hendrix J. W., Apple J. L. 1964. Fats and fatty acid derivatives as growth stimulants and carbon sources for Phytophthora parasitica var. nicotianae. Phytopathology 54: 987-994.

[ISTA] International Seed Testing Association 1993. International rules for seed testing. Seed Science and Technology 21 Supplement Rules.

KLICH M. A. 1986. Mycoflora of cottonseed from the southern United States: A three year study of distribution and frequency. Mycologia 78: 706-712.

Li X. C. Jacob M. R., Elsohly H. N., Nagle D. G., Smillie T. J., Walker L. A. 2003. Acetylenic acids inhibiting azole-resistant Candida albicans from Pentagonia gigantifolia. J. Nat. Prod. 66: 1132-1135.

Liu S. Ruan W., Li J., Xu H., Wang J., Gao Y., Wang J. 2008. Biological control of phytopathogenic fungi by fatty acids. Mycopathologia 166: 93-102.

Mezhlum-YanL. G., Redina E. F., Kasymova G. A., Yuldashev K. H., Khodzhibaera S. M. 1994. Functional properties of a serine protease inhibitor from cottonseeds. Chem. Nat. Compounds 30: 492-495.

Mohamed-Hoda Z., Fatma H., Salem A., El-Wakil A. A. 1999. Effect of cottonseed delinting on seed-borne fungi, emergence, and seedling disease incidence. Egy. J. Agric. Res. 77: 10071021.

Nelson S. G., Campbell C. L. 1992. Incidence and patterns of association of pathogens of a leaf spot disease complex on white clover in the Piedmont region in North Carolina. Phytopathology 82: 1013-1021.

Podleckis E. V., Crutis C. R., Heggestad H. E. 1984. Peroxidase enzyme markers for ozone sensitivity in sweet corn. Phytpathology 74: 572-577. 
Roncadori R. W., Mccarter S. M., Crawford M. 1971. Influence of fungi on cottonseed deterioration prior to harvest. Phytopathology 61: 1326-1328.

Ruttledge T. R., Nelson E. R. 1997. Extracted fatty acids from Gossypium hirsutum stimulatory to the seed-rotting fungus, Pythium ultimum. Phytochemistry 46: 77-82.

Salunkhe D. K., Chavan J. K., Adsule R. N., Kadam S. S. 1992. World Oilseeds: Chemistry, Technology, and Utilization. Van Nostrand Reinhold,New York.

Simpson M. E., Marsh P. B., Merola G. V., Ferrett R. J., Filsinger E. G. 1973. Fungi that infect cottonseeds before harvest. Appl. Microbiol. 26: 608-613.

Vogel A. J. 1975. A Text Book of Practical Original Chemistry, $3^{\text {rd }}$ Ed. English Language Book Society and Longman Group Ltd., London.

Waked M. Y., El-Samra I. A., FAYed M. A. 1981. Histological studies on cotton seeds infected with some rotting fungi. Phytopathol. Mediterr. 20: 136-140.

Walters D., Raynor L., Mitchell A., Walker R., Walker K. 2004. Antifungal activities of four fatty acids against plant pathogenic fungi. Mycopathologia 157: 87-90.

Walters D. R., WAlKer R. L., WalKer K. C. 2003. Lauric acid exhibits antifungal activity against plant pathogenic fungi. J. Phytopathol. 151: 228-230.

Wilson R. A., Calvo A. M., Chang P. K., Keller N. P. 2004. Characterization of the Aspergillus parasiticus $\Delta^{12}$-desaturase gene: a role for lipid metabolism in the Aspergillus-seed interaction. Microbiol. 150: 2881-2888.

Xue H. Q., Upchurch R. G., Kwanyuen P. 2008. Relationships between oleic and linoleic acid content and seed colonization by Cercospora kikuchii and Diaporthe phaseolorum. Plant Dis. 92: 1038-1042.

Zayed S. M. E. 1997. Studies on foliar diseases of cotton. Ph.D. Thesis, Mansoura Univ., Mansoura. 